\title{
Pengaruh Karakteristik Pekerjaan Terhadap Keterikatan Dalam Pekerjaan Pada Maskapai Penerbangan Indonesia
}

\author{
Gian Rachmana Putra* dan Sri Raharso \\ Jurusan Administrasi Niaga, Politeknik Negeri Bandung, Indonesia
}

\begin{abstract}
:
The purpose of this research is to find out how the work characteristics model impacts the involvement of employees in Indonesian airlines. The job characteristic model has a core dimension that is variation in skills, task significance, task identity, autonomy, and feedback. Employee involvement has three dimensions, namely passion, dedication, and absorption. Data analysis conducted in this study is the result of the current distribution to 172 airline employees. The results of the descriptive analysis of each variable in this study indicate that the model of job characteristics and employee involvement is classified as good. The results of data processing in this study indicate that there is a positive impact of job characteristics for employee involvement, which means that any addition to the value of the job characteristics model will affect employee involvement. From this study, it can be seen that $22 \%$ employee involvement is influenced by the work characteristic model and $78 \%$ is influenced by other things not discussed in this study.
\end{abstract}

Keywords: job characteristics model, employee engagement, airline

\begin{abstract}
Abstrak:
Tujuan diadakannya penelitian ini adalah untuk mengetahui bagaimana model karakteristik pekerjaan berdampak terhadap keterlibatan karyawan yang ada di maskapai penerbangan Indonesia. Model karakteristik pekerjaan memiliki limadimensi inti yaitu variasi keterampilan, signifikansi tugas, identitas tugas, otonomi, dan umpan balik. Keterlibatan karyawan memiliki tiga dimensi, yaitu semangat, dedikasi, dan penyerapan. Analisis data yang dilakukan dalam penelitian ini adalah hasil distribusi yang sekarang ke 172 karyawan maskapai penerbangan. Hasil analisis deskriptif dari masing-masing variabel dalam penelitian ini menunjukkan bahwa model karakteristik pekerjaan dan keterlibatan karyawan tergolong baik. Hasil pengolahan data pada penelitian ini menunjukkan bahwa terdapat dampak positif dari karakteristik pekerjaan untuk keterlibatan karyawan, yang berarti bahwa setiap penambahan nilai dari model karakteristik pekerjaan maka akan mempengaruhi pada keterlibatan karyawan. Dari penelitian ini, dapat diketahui bahwa keterlibatan karyawan 22\% dipengaruhi oleh model karakteristik pekerjaan dan $78 \%$ dipengaruhi oleh hal-hal lain yang tidak dibahas dalam penelitian ini.
\end{abstract}

Kata kunci: model karakteristik pekerjaan, keterlibatan karyawan, maskapai penerbangan

\section{Pendahuluan}

Indonesia sebagai negara kepulauan terbesar dan padat penduduk menjadikan Indonesia sebagai pasar membuka kesempatan besar kepada industri penerbangan untuk berkembang. Tercatat oleh Direktorat Jendral Perhubungan Udara Kementrian Perhubungan Republik Indonesia, pertumbuhan jasa penrbangan pada tahun 2014 mencapai 674.853 kedatangan baik domestik dan internasional serta 670.004 keberangkatan baik domestik dan internasional. Jumlah penumpang yang tercatat mencapai 
angka 87.108.931 kedatangan dan 71.290.074 penumpang tiba. Namun demikian pada pertengahan tahun 2018 aktifitas penerbangan mengalami penurunan dari pada tahun 2017, hal ini tidak membuat industri penerbangan mengalami penurunan performa. Bahkan pada tahun 2017 pertumbuhan industri penerbangan tergolong pesat dengan bertambahnya 82 rute penerbangan yang dilakukan oleh berbagai perusahaan penyedia jasa transportasi udara. Hal ini membuktikan bahwa aktifitas penerbangan yang terjadi masih memiliki potensi untuk terus berkembang meskipun terjadi penurunan aktifitas penerbangan.

Citilink Indonesia adalah maskapai penerbangan yang didirikan oleh PT Garuda Indonesia sebagai unit strategi bisnis untuk meningkatkan daya saing perusahaan dalam hal pelayanan penerbangan. Dimana pada awal tahun 2000-an trend penerbangan berbiaya rendah (Low Cost Carrier/LCC) menjadi hal yang menjanjikan untuk masyarakat Indonesia. Selain itu Citilink juga diharapkan menjadi andalan Garuda Indonesia dalam persaingan penerbangan berbasis LCC. Terbukti semenjak didirikan pada tahun 2009 Citilink tumbuh pesat dan menjadi maskapai penerbangan LCC yang akrab oleh masyarakat Indonesia. Tercatat pada akhir 2017 yang lalu jumlah rute penerbangan yang sediakan oleh Citilink berjumlah 62 rute penerbangan domestik serta 50 armada pesawat yang siap melayani masyarakat Indonesia. Selain itu Citilink juga terus berkembang dan berkontribusi dalam industri penerbangan, hal ini dibuktikan dengan diperolehnya beberapa penghargaan dan sertifikasi yang diberikan kepada perusahaan. Adapun penghargaan dan sertifikasi yang didapatkan Citilink dalam kurun waktu lima tahun terakhir adalah sebagai berikut:

1. TOP IT Implementation on Airlines Sector pada Nopember 2017 sebagai maskapai yang menerapkan pelayanan digital untuk memberikan kemudahan pelanggannya dan perusahaan secara keseluruhan yang diselenggarakan oleh Itech Magazine dan Kementerian Komunikasi dan Informatika RI.

2. Pahlawan Ekonomi dari Pemerintah Kota Surabaya pada November 2017 sebagai mitra pemerintah Kota Surabaya yang mendukung ekonomi kerakyatan di Surabaya yang diselenggarakan Pemerintah Kota Surabaya.

3. Indonesia Leading Low Cost Airline 2017/2018 pada Desember 2017 Sebagai Maskapai Berbiaya Hemat (LCC) Indonesia yang banyak digunakan oleh pelaku wisata di Indonesia yang diselenggarakan Indonesia Travel and Tourism Organization.

4. Transportation Safety Management Award 2017 pada Desember 2017 Sebagai Maskapai LCC Indonesia yang selalu menerapkan dan mengedepankan faktor keamanan dalam proses pre-flight, in-flight dan post-flight diselenggarakan oleh Kementerian Perhubungan RI.

Sebagai perusahaan berbais jasa (pelayanan) tentu saja aspek sumber daya manusia sangat berperan penting dalam pencapaian yang telah diraih perushaan. Berbagai prestasi tersebut tidak lepas dari peranan karyawan sebagai sumber daya yang vital. Hal ini selaras dengan yang diungkapkan oleh Noe et al. (2011) bahwa manajemen sumber daya manusia merupakan kunci dalam keberhasilan sebuah perusahaan dalam bertahan hidup (survival), efektifitas, dan daya saing. Maka dengan peran yang penting tersebut dalam praktiknya melalui kebijakan dan sistem manajemen sumber daya manusia yang diterpakan mampu mempengaruhi prilaku, sikap, dan kinerja karyawan. Hubungan antara organisasi dengan manusia layaknya simbiosis yang saling menguntungkan, dimana organisasi membutuhkan efektifitas kerja dari manusia dalam meningkatkan nilai dalam pasar. Sedangkan manusia juga membutuhkan perusahan bukan sekedar upah namun sebagai sarana meningkatkan harga diri dan kualitas hidup (Schiemann, 2011).

Beberapa peneliti mengungkapkan bahwa untuk mencapai keunggulan kompetitif (Competitive Advantage) hal terpenting bagi perusahaan adalah untuk mengikat karyawan (Engaging Employee). Karena dengan adanya employee engagement (keterikatan karyawan dengan perusahaan) dapat meningkatkan keunggulan bersaing yang berimbas positif terhadap perusahaan (Buckingham \& Coffman, 199; Harter et al, 2002, Scheiman, 2011). Employye engagement merupakan pemahaman yang dikembangkan oleh peneliti sebagai evolusi dari pemahaman terkait kepuasan dan komitmen karyawan (Simon 2009; Schiemann, 2011). Istilah Employee Engagement sendiri pertama kali dikembangkan oleh William Khan seorang profesor di Boston School of Management pada tahun 1990. Khan berangapan bahwa employee engagement merupakan pengembangan multidimensi, artinya bahwa keterikatan karyawan pada sebuah perusahaan melibatkan keterikatan secara emosional, kognitif, dan phisikologis. Dan fakta dilapangan membuktikan bahwa employee engagement 
merupakan faktor utama dalam menentukan kekuatan sebuah perusahaan atau company's vigor. (Sarder et al, 2011)

Berdsarakan tingkat kebutuhan dari employee engagement tersebut para peneliti mengembangkan tentang faktor-faktor pendahulu (anteseden) serta pengaruh terhadap hasil dari employee engagement tersebut. Hasil dari bebrapa penelitian tersebut beragam, namun terdapat tiga faktor yang sering digunakan sebagai faktor kuat pemicu employee engagement. Faktor-faktor tersebut yaitu job characteristics, supervisor support, dan reward management (Khan, 1990; Slatten \& Mehmetougli, 2011). Job characteristcs memiliki komponen yang dapat memicu pemahaman mendalam terkait pekerjaan, rasa tanggung jawab terhadap hasil, rasa peduli terhadap dampak dari pekerjaan, serta menimbulkan norma positif untuk karyawan (Hackman \& Oldham, 1980). Supervisor support adalah kesedian manajer dan supervisor sebuah perusahaan untuk berdiskusi, bertukar pemahaman, dan bersedia menampung aspirasi para karyawan (Schiemann, 2011). Sedangkan reward adalah timbal balik yang didapat oleh karyawan atas kinerjanya (Maslach et al, 2001).

Keterlibatan yang tinggi atas pekerjaan dapat dipengaruhi oleh karakteristik pekerjaan itu sendiri. Hackman \& Oldham (1980) beranggapan bahwa apabila seseorang merasa nyaman dengan pekerjaannya, tidak perlu memnaipulasi, memaksa, dan menyuap karyawan mereka akan memberikan kinerja terbaik yang dapat diberikan. Job characteristcs merupakan pendekatan dari analysis and design of work. Tujuan dari konsep tersebut adalah mendesin sutu pekerjaan agar dapat memberikan motivasi lebih terhadap sumberdaya yang mengerjakannya (Hackman \& Oldham, 1980). Untuk mengidentifikasi job characteristics terdapat lima dimensi yang harus diperhatikan yaitu skill variety, taks identity, task significance, autonomy, feedback. Dari pemaparan tersebut penelitian ini bertujuan untuk mengetahui bagaimana keterkaitan antara karakteristik pekerjaan yang dimiliki perusahaan maskapai penerbangan Indonesia terhadap employee engagement sehingga perusahaan mampu memberikan pelayanan terbaik dan mampu bersaing dalam ketatnya dunia industri penerbangan.

\section{Kajian Literatur}

\subsection{Job Characteristics Model}

Konsep karakteristik pekerjaan ini pertama kali dikemukakan oleh Hackman dan Oldham pada tahun 1980, mereka menjelaskan bahwa job characteristics model merupakan pendekatan dalam merancang sebuah pekerjaan. job characteristics model adalah tahap lanjut dari rancangan pekerjaan. Pendekatan ini berupaya untuk menjelaskan situasi pekerjaan dan merancang agar suatu pekerjaan dapat berjalan efektif bagi individu dengan menggunakan pendekatan contigency (Kreitner dan Kinicki, 2007). Dimensi inti dari karakteristik pekerjaan ini selanjutnya digambarkan sebagai berikut :

1. Keanekaragaman keterampilan (skill variety) adalah tingkat sampai dimana pekerjaan memerlukan individu yang mampu melakukan berbagai tugas yang mengharuskannya menggunakan keterampilan dan kemampuan yang berbeda.

2. Indentitas tugas (taks identity) : tingkat sampai dimana suatu pekerjaan membutuhkan penyelesaian dari seluruh proses bagian pekerjaan yang diidentifikasikan.

3. Arti tugas (task significance) adalah tingkat sampai dimana pekerjaan berpengaruh substansial dalam kehidupan atau pekerjaan individu lain.

4. Otonomi (autonomy) : tingkat sampai dimana suatu pekerjaan memberikan kebebasan, kemerdekaan serta keleluasaan yang substansial untuk individu dalam merencanakan pekerjaan dan menentukan prosedur-prosedur yang akan digunakan untuk menjalankan pekerjaan tersebut.

5. Umpan balik (feedback) adalah tingkat sampai dimana pelaksanaan aktivitas kerja membuat seseorang individu mendapatkan informasi yang jelas dan langsung mengenai keefektifan kerjanya.

\subsection{Employee Engagement}

Konsep engagement at work atau keterikatan dalam pekerjaan pertamakali dikemukakan oleh Khan tahun (1980) konsep tersebut adalah sebagai berikut : organisasi memanfaatkan anggota sesuai dengan perannya masing-masing; dalam keterikatan, karyawan memberikan dirinya secara fisik, kognitif, dan emosinya melebihi dari peran yang harus ia jalankan. Apabila karyawan memiliki employee engagement artinya mereka memiliki perasaan emosional positif terhadap apa pekerjaan mereka, sadar dengan arti penting pekerjaan mereka, dan sadar bahwa beban pekerjaan mereka masih dapat dikelola 
serta masih memiliki potensi yang menjanjikan di masa yang akan datang. Sehingga, dengan adanya employee engagement perusahaan tidak perlu memaksa karyawan, sebaliknya mereka akan dengan sendirinya memberikan kemampuan terbaik dalam melaksanakan pekerjaannya.

Adapun menurut sebuah penelitian yang dilakukan di Mertus Institute (dalam Schieman, 2011) menganggap bahwa karyawan dapat dikatakan engage apabila dapat melakukan hal sebagai berikut:

1. Apabila seorang yang cenderung netral dalam bekerja dapat memiliki kemampuan untuk menarik keluar emosi positif tentang perusahaan (seperti bertekad ikut serta dalam kegiatan penunjang kesuksesan perusahaan) dan memiliki tingkat energi kegembiraan saat berada dalam lingkungan kerja.

2. Dapat dengan mudah mengetahui prilaku penting rekan kerja, mengetahui hal-hal yang dapat memacu semangat dan mengetahui tekan apa yang dapat mempengaruhi kinerja.

3. Dapat dengan mudah beradaptasi dengan kebijakan yang diambil perusahaan atau supervisor.

Dengan kata lain tingkat tertinggi dari engagement adalah saat seorang karyawan rela melakukan tindakan lebih dari yang ditugaskan dengan suka rela. Para peneliti menganggap kejadian tersebut sebagai sebuah sikap organisasi yang terdiri dari tiga bagian dimensi vigor, dedication, dan absorption. Vigor diidentikan dengan tingkat keinginan yang besar, energi, dan semangat pantang menyerah dalam menghadapi tantangan. Dedication diidentifikasi dengan merasa organisasi sangat berharga, sehingga menimbulkan antusias dalam bekerja dan memancing terjadinya semangat dalam menghadapi tantangan. Absorption ditandai dengan adanya fokus secara maksimal terhadap pekerjaan sehingga dapat menyerap banyak informasi dengan cenderung lebih mudah. Gallup Organization melihat seorang karyawan dengan 'rasa terikat' yang tinggi atau highly engaged adalah seseorang yang secara psikologis berkomitmen terhadap tugas dan perannya. Gallup, membagi karyawan dalam tiga kategori sebagai berikut:

1. Karyawan yang terikat (engaged employees): karyawan yang bekerja dengan semangat dan merasakan hubungan yang dalam dengan perusahaan mereka. menjadi bagian dari lahirnya ide-ide inovatif yang memajukan perusahaan.

2. Karyawan yang tidak terikat (not-engaged employees): karyawan secara praktis mereka tidak lagi memikirkan kemajuan perusahaan. Mereka datang untuk bekerja, tetapi tidak cukup memberikan energi atau semangat dalam pekerjaannya.

3. Karyawan yang Lepas (actively disengaged employees): karyawan yang bukan hanya tidak puas dengan tempat kerjanya, bahkan secara terbuka menampakkan ketidakpuasannya di tempat kerja; seolah menumpang atau bahkan menggerogoti apa yang dihasilkan oleh rekan-rekan kerjanya.

Namun demikian bukan berarti emploeyee engagement tidak dapt dibentuk. Karena pada dasarnya engagement dapat dipicu oleh beberapa hal. Alan M. Saks (2005) mengembangkan konsep yang dimiliki Khan sehingga mendapat kesimpulan bahwa terdapat faktor pemicu engagement, yaitu :

1. Job Characteristics

Job characteristics merupakan konsep yang dikembangkan oleh Hackman dan Oldham (1980) yang terdiri dari lima dimensi yaitu skill variety, task identity, task significance, autonomy dan feedback. Selain kelima dimensi tersebut menurut Maslach (2001) faktor beban kerja dan pengawasan juga berpengaruh terhadap engagement dan dalam pelaksanaannya autonomy dan feedback erat kaitannya dengan burnout.

2. Rewards dan recognition

Timbal balik berupa penghargaan dan pengakuan atas kinerja merupakan faktor yang penting bagi karyawan untuk meningkatkan ikatan terhadap perusahaan. Maka dari itu karyawan pada umumnya memilih perusahaan yang dapat memberi timbal balik yang lebih dari pada kinerja yang dia hasilkan. Maslach (2001) menjelaskan bahwa rendahnya pengakuan dan penghargaan atas kinerja mengarah terhadap adanya penurunan terhadap engagement karyawan.

3. Perceived Organizational Support (POS)

POS adalah konsep di mana sebuah perusahaan menganggap bahwa penting untuk memperhatikan kesejahteraan karyawan. Sehingga karyawan percaya bahwa kinerja mereka akan dihargai. Hal itu menyebabkan perusahaan cenderung mudah dalam mencapai tujuan. (Rhoades dan Eisenberger, 2002) 
Marcino (2010) menyebutkan bahwa employee engagement bergantung pada lima faktor dimensi yaitu organisasi, kepemimpinan, anggota tim, pekerjaan dan individu. Sedangkan menurut Schaufeli \& Bakker (2003) dimensi atau faktor-faktor dari employee engagement terdiri dari tiga yaitu :

1. Vigor

Faktor ini diidentifikasi sebagai tigginya tingkat kekuatan dan resiliensi mental dalam bekerja, keinginan untuk berusaha dengan sekuat tenaga di dalam pekerjaan serta gigih dalam menghadapi kesulitan.

2. Dedication

Faktor ini diidentifikasikan oleh suatu perasaan yang penuh penghayatan, antusiasme, inspiratif, kebanggaan dan menantang dalam pekerjaan. Orang-orang yang memiliki skor dedication tinggi secara kuat berkomitment pada pekerjaan mereka karena merasa pekerjaan sebagai pengalaman berharga, menginspirasi dan merasa tertantang. Selain itu, skor rendah pada dedication menandakan tidak terjadinya komitment individu kepada pekerjaan karena mereka merasa tidak mendapat pengalaman berharga, tidak merasa terinspirasi dan merasa tidak mendapat tantangan atau dapat dengan mudah merasa jenuh dalam pekerjaan.

3. Absorption

Faktor ini ditandai dengan adanya konsentrasi dan minat yang mendalam, fokus pada pekerjaan, waktu terasa cepat berjalan dan individu sulit melepaskan diri dari pekerjaan sehingga dapat melupakan segala sesuatu yang ada disekitarnya. Orang-orang yang memiliki skor tinggi pada absorption biasanya merasa senang perhatiannya tersita oleh pekerjaan, merasa tenggelam dalam pekerjaannya dan memiliki kesulitan untuk memisahkan diri dari pekerjaan. Akibatnya, apapun disekelilingnya terlupakan dan waktu cepet berlalu. Sebaliknya orang dengan skor absorption rendah mengakibatkan mereka tidak merasa nyaman dan tidak tenggelam dalam pekerjaannya, tidak memiliki kesulitan untuk berpisah dengan pekerjaan dan tidak melupakan segala sesuatu disekeliling mereka, termasuk waktu.

\section{Metode Penelitian}

Penelitian ini enggunakan metode kuantitatif karena dengan metode tersebut dapat lebih efektif untuk mengkaji rumusan masalah untuk mengambil jawaban atas permasalah terkait pengaruh job characteristics model terhadap employee engagement. Dalam penelitian ini terdapat dua variabel yang berperan, yaitu variabel independen dan variabel dependen, karena dalam metode penelitian kuantitatif memiliki hubungan sebab akibat. Kemudian kedua variabel tersebut akan diukur seberapa besar pengaruh variabel independen (variabel X) terhadap variabel dependen (Variabel Y) (Sugiyono, 2013).

\subsection{Populasi dan Sampel}

Populasi merupakan wilayah generalisasi yang terdiri dari objek atau subjek yang memiliki kualitas dan karakteristik tertentu yang ditetapkan oleh peneliti untuk dipelajari yang kemudian dapat ditarik kesimpulan (Sugiyono, 2013). Populasi dalam penelitian ini adalah karyawan kantor Citilink Indonesia yang berjumlah 300 orang.

Teknik sampling adalah langkah yang diambil untuk mempermudah dalam menentukan sampel. Teknik sampling yang digunakan adalah probility sampling dengan cara pengambilan sampel menggunakan simple random sampling. Probability sampling merupakan teknik pengambilan sampel dimana setiap individu dalam populasi (secara sendiri-sendiri atau berkelompok) diberi kesempatan yang sama untuk terpilih sebagai anggota sampel (Sugiyono, 2013). Sedangkan simple random sampling menurut Sugiyono (2013) adalah tehnik sampling dengan cara acak tanpa memerhatikan strata yang terdapat dalam populasi tersebut. Dalam penelitian ini yang menjadi sampel yang peneliti ambil berdasarkan rumus yang di kemukakan Solvin (dalam Riduwan, 2014) dalam menentukan sampel yang paling tepat tergantung pada tingkat kesalahan yang dikehendaki. Pedoman menentukan jumlah sampel adalah sebagai berikut:

dimana:

$$
\mathrm{n}=\frac{N}{1+\mathrm{Ne}^{2}}
$$

$\mathrm{n} \quad=$ jumlah sampel

$\mathrm{N}=$ jumlah populasi 
$\mathrm{E}=$ batas toleranso kesalahan (error tolerance)

Dalam peneliti ini menurut Sugiyono (2015) tingkat ketepatan dalam penelitian terkait bidang sosial dan masyarakat diaharpkan memiliki tingkat akurasi sebesar 95\%, maka dari itu dalam penelitian ini tingkat kesalahan yang dapat ditolerir sebesar 5\% yang artinya dalam penelitian ini perhitungan terkait sampel yang digunakan adalah sebagai berikut :

$$
\mathrm{n}=\frac{300}{1+300(5 \%)^{2}}
$$

dimana hasil akhir 171, 4285 yang digenapkan menjadi 172 responden

\subsection{Teknik Pengumpulan Data}

Teknik pengumpulan data adalah cara-cara yang ditempuh dan alat-alat yang digunakan oleh peneliti dalam mengumpulkan data (Darmawan, 2013). Peneliti menggunakan teknik kuesioner (angket) dalam pengumpulan datanya. Kuesioner merupakan teknik pengumpulan data yang dilakukaan dengan cara memberi seperangkat pertanyaan atau pernyataan tulisan kepada responden untuk dijawab (Sugiyono, 2013). Kuesioner merupakan salah satu sumber data primer. Sedangkan data sekunder yang peneliti gunakan adalah data yang dimiliki perusahaan yang berkaitan dengan penelitian ini.

\subsection{Teknik Analisis Data}

Teknik analisis data yang digunakan dalam penelitian ini adalah menggunakan regresi ganda. Sedangkan untuk uji prasyarat analisisnya meliputi, uji normalitas, linearitas, heteroskedastisitas. Uji hipotesis terdiri dari mencari koefisien determinasi $\left(\mathrm{R}^{2}\right)$ dan uji parsial (uji t).

\section{Hasil dan Pembahasan}

\subsection{Identitas Responden}

Responden dari penelitian ini berjumlah 172 karyawan perusahaan penerbangan Citilink Indonesia. Analisis identitas responden diuraikan menjadi beberapa bagian yaitu jenis kelamin, usia, pendidikan, dan lamanya bekerja yang dimiliki responden. Berdasarkan jenis kelamin, yang lebih mendominasi yaitu pria dengan $74 \%$ atau sebanyak 128 orang. Persentase jenis kelamin wanita sebesar $26 \%$ atau sebanyak 44 orang. Mayoritas dari responden memiliki rentang usia 31 hingga 40 tahun. Pada usia 41 50 tahun sebesar $17 \%$, usia $<30$ tahun mempunyai persentase yaitu sebesar $25 \%$. Untuk usia lebih dari dari 50 tahun memiliki persentase sebesar $8 \%$ dari jumlah responden. Pendidikan terakhir dari responden mayoritas yaitu S1/D4. Hal itu diketahui dari hasil persentase sebesar $65 \%$ atau sebanyak 112orang. Kemudian lulusan S2/S3 menempati posisi kedua tertinggi dengan $15 \%$ atau setara dengan 25 orang, disusul SMA/SMK 9\% (16orang) dan D1/D2/D3 sebesar 8\% (13 orang) dan terakhir yang menempuh jalur pendidikan lain terdapat 3\% setara dengan 6 orang. Mayoritas responden adalah karyawan yang baru bekerja di perusahaan tersebut selama kurang dari lima tahun, $62 \%$ atau setara dengan 106 orang responden. Kemudian disusul dengan karyawan dengan lama bekerja antara 6 - 10 tahun sebesar 30\%, dan sisanya 5\% diatas 15 tahun sedangkan hanya 3\% yang dibawah 5 tahun.

\subsection{Uji Asumsi Klasik}

Gambar 1 berikut merupakan metode Grafik Normal P-P Plot dengan nilai signifikansi tidak kurang dari $(<0,05)$. Dilihat pada gambar 1 diatas dapat dijelaskan bahwa data yang didapat berdistribusi normal dengan melihat titik-titik pada gambar menyebar dan searah dengan garis diagonalnya. Menurut Sugiyono (2017: 268) bahwa pengujian normalitas data itu dapat dilakukan dengan beberapa metode diantaranya metode grafik dimana dijelaskan apabila titik-titik pada grafik normal P-P Plot ini mengikuti garis diagonalnya maka dapat dikatakan data terdistribusi secara normal. Menurut Priyatno (2014: 94) menjelaskan metode grafik pada pengujian data normalitas residual yakni dengan melihat penyebaran data pda sumber diagonal pada grafik normal $P-P$ Plot of regression standardized residual maka nilai residual tersebut telah normal.

Pada tabel 1 dapat dilihat bahwa sebanyak 172 responden didapat sebagai sampel pada pengujian linieritas melalui metode test for linearity SPSS 22.0 maka didapat lah hasil seperti dibawah ini. Uji dari keseluruhan sampel juga dihasilkan tingkat signifikansi linearity nya 0,000 kurang dari 0,05 maka dikatakan bahwa variabel $\mathrm{x}$ dan $\mathrm{y}$ ini saling berhubungan. 


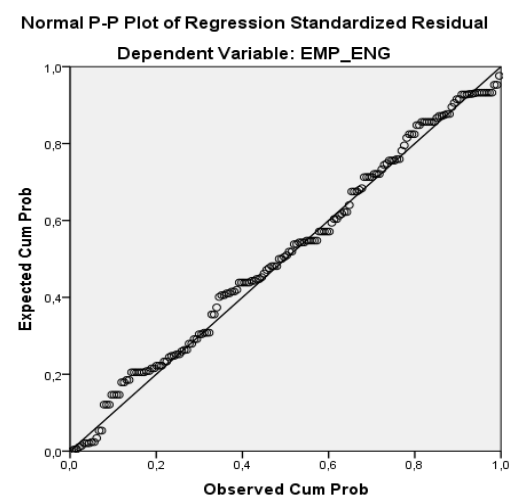

Gambar 1 Probability Plot

Tabel 1 Uji Linieritas

\begin{tabular}{|l|ll|c|c|c|c|c|}
\hline \multicolumn{2}{|c|}{} & $\begin{array}{c}\text { Sum of } \\
\text { Squares }\end{array}$ & Df & $\begin{array}{c}\text { Mean } \\
\text { Square }\end{array}$ & F & Sig. \\
\hline $\begin{array}{l}\text { EMP_ENG } \\
\text { JCM }\end{array}$ & Between Groups & (Combined) & 4215,377 & 19 & 221,862 & 6,037 & 0,000 \\
\cline { 2 - 9 } & & Linearity & 2204,179 & 1 & 2204,179 & 59,974 & 0,000 \\
\cline { 2 - 8 } & Deviation from Linearity & 2011,198 & 18 & 111,733 & 3,040 & 0,000 \\
\cline { 2 - 9 } & Within Groups & 5586,321 & 152 & 36,752 & & \\
\hline
\end{tabular}

Scatterplot

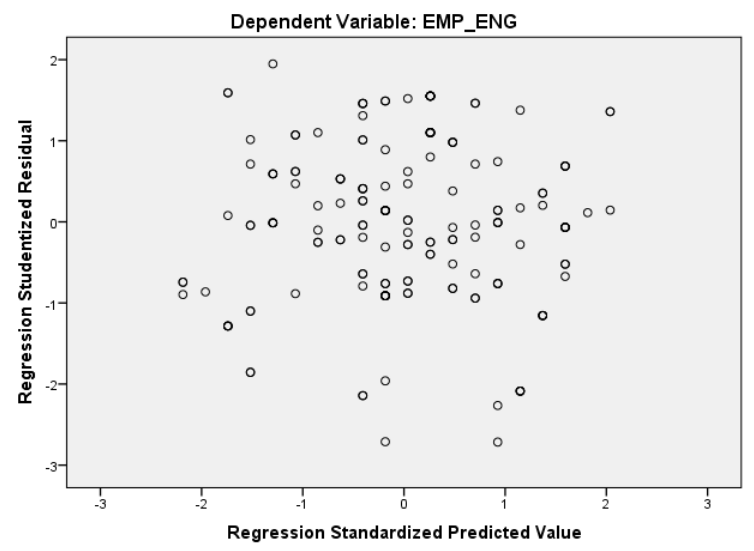

Gambar 2 Grafik Heterokedastisitas

Uji heterokedastisitas ini merupakan prasyarat pada pengujian regresi linier sederhana ada beberapa metode analisis salah satunya yakni menggunakan Grafik seperti pada gambar 2. Dapat dilihat pada grafik diatas bahwa bentuk titik-titik atau lingkarang-lingkaran kecil diatas tidak membentuk pola tertentu dikatakan pada penelitian ini tidak terjadi kendala heteroskedastisitas. Menurut Priyatno (2014: 115) menjelaskan bahwa dapat diketahui kendala heteroskedastisitas dari grafik titik-titik yang tidak membetuk pola secara jelas, dan titik-titik tersebut menyebar diatas dan dibawah angka 0 pada sumbu Y. Maka dapat disimpulkan bahwa tidak terjadi masalah heteroskedastisitas pada model regeresi.

\subsection{Analisis Deskriptif}

Berdasarkan Tabel 2, dapat diketahui bahwa tingkat job characteristcs model karyawan maskapai penerbangan Indonesia berada pada kategori "baik" dengan nilai 4,20 yang terlihat dari nilai mean karena berada pada rentang nilai 3,40 - 4,20. Dari lima dimensi job characteristcs model, dimensi task significance merupakan dimensi yang memiliki mean tertinggi dari lainnya yaitu sebesar 4,50, sedangkan feedback merupakan dimensi terrendah dengan nilai rata-rata 3,92. Selain itu, dapat 
diketahui bahwa rata-rata responden memiliki tingkat variasi jawaban yang rendah. Hal itu dapat dilihat melalui nilai standar deviasi sebesar 0.47799 atau $12.38 \%$ karena nilai standar deviasi di bawah $20 \%$.

Tabel 2 Analisis Deskriptif Variabel JCM

\begin{tabular}{|l|r|r|r|r|r|r|}
\hline & \multicolumn{1}{|c|}{$\mathrm{N}$} & \multicolumn{1}{|c|}{ Minimum } & \multicolumn{1}{c|}{ Maximum } & \multicolumn{2}{|c|}{ Mean } & Std. Deviation \\
\cline { 2 - 7 } & Statistic & \multicolumn{1}{c|}{ Statistic } & Statistic & Statistic & Std. Error & Statistic \\
\hline Skill Variety & 172 & 3,00 & 5,00 & 4,2907 & 0,04860 & 0,63736 \\
\hline Task Significance & 172 & 3,00 & 5,00 & 4,5058 & 0,04554 & 0,59724 \\
\hline Taks Identity & 172 & 3,00 & 5,00 & 4,2442 & 0,05336 & 0,69981 \\
\hline Autonomy & 172 & 2,00 & 5,00 & 4,1163 & 0,05763 & 0,75577 \\
\hline Feedback & 172 & 2,00 & 5,00 & 3,9244 & 0,05408 & 0,70924 \\
\hline JCM & 172 & 3,00 & 5,00 & 4,2093 & 0,03975 & 0,52127 \\
\hline
\end{tabular}

Sumber: Olah Data SPSS (2018)

Tabel 3 Analisis Variabel Employee Engagement

\begin{tabular}{|l|r|r|r|r|r|r|}
\hline \multirow{2}{*}{} & \multicolumn{1}{|c|}{$\mathrm{N}$} & \multicolumn{1}{c|}{ Minimum } & \multicolumn{1}{c|}{ Maximum } & \multicolumn{2}{|c|}{ Mean } & Std. Deviation \\
\cline { 2 - 7 } & Statistic & Statistic & \multicolumn{1}{c|}{ Statistic } & Statistic & Std. Error & \multicolumn{1}{c|}{ Statistic } \\
\hline Vigor & 172 & 2,00 & 5,00 & 4,0000 & 0,05215 & 0,68399 \\
\hline Dedication & 172 & 3,00 & 5,00 & 4,4302 & 0,04211 & 0,55231 \\
\hline Absorption & 172 & 3,00 & 5,00 & 3,8953 & 0,04812 & 0,63114 \\
\hline Employee Engagement & 172 & 3,00 & 5,00 & 4,0814 & 0,04474 & 0,58670 \\
\hline
\end{tabular}

Sumber: Olah Data SPSS (2018)

Berdasarkan Tabel 3, dapat diketahui bahwa tingkat Employee Engagement karyawan maskapai penerbangan Indonesia berada pada kategori "baik" dengan nilai 4,08 yang terlihat dari nilai mean karena berada pada rentang nilai 3,40 - 4,20. Dari ketiga dimensi Employee Engagement, dimensi dedication merupakan dimensi yang memiliki mean tertinggi dari lainnya yaitu sebesar 4,43 . Sedangkan dimensi dengan nilai rata-rata terrendah adalah dimensi absorption dengan nilai rata-rata 3,89. Selain itu, dapat diketahui bahwa rata-rata responden memiliki tingkat variasi jawaban yang rendah. Hal itu dapat dilihat melalui nilai standar deviasi sebesar $13.63 \%$ karena nilai standar deviasi dibawah $20 \%$.

\subsection{Analisis Regresi Sederhana}

Tingkat nilai koefisien determinasi dalam penelitian ini pengaruh job characteristcs model terhadap employee engagement. Menurut priyatno (2014: 141) menyatakan bahwa nilai $\mathrm{R}$ merupakan bentuk korelasi berganda yang menjelaskan korelasi antara 2 atau lebih variabel independen terhadap dependen, tetapi dalam regresi sederhana $\mathrm{R}$ ini merupakan Korelasi Pearson antara Variabel $\mathrm{X}$ terhadap Y. Berdasarkan hasil dari pengujian koefisien determinasi $\left(\mathrm{Uji}^{2}\right.$ ) maka dapat dikatakan bahwa korelasi antara variabel $\mathrm{x}$ terhadap variabel y itu sebesar 0,225. Maka dapat dikatakan bahwa hubungan antara variabel kualitas pelayanan terhadap variabel partisipasi anggota koperasi rendah karena nilainya mendekati 0 (nol). Menurut Priyatno (2014: 142) menjelaskan bahwa pengaruh x terhadap y tingkatan persentasenya dapat dilihat pada tabel $\mathrm{R}^{2}$. Maka dari $\mathrm{R}^{2}$ yang dihasilkan dapat dikatakan pengaruh yang dihasilkan hanya sebesar $22 \%$ karena berdasarkan data tabel yang diubah ke dalam satuan persen.

Berdasarkan ketentuan dan rumus dalam pengujian regresi linier sederhana dari output koefisien regresi dimasukan kedalam rumus regresi linier sederhana diatas. Maka didapat hasil sebagai berikut:

$$
\mathrm{Y}=24,792+0,798 \mathrm{X}
$$

Penjelasan (a) adalah 24,792 yakni dapat diartikan bahwa jika job characteristics model 0, maka employee engagement yang dimiliki karyawan bernilai 24,792. Nilai koefisien regresi varabel job characteristics model bernilai positif yakni 0,798; maka dapat diartikan bahwa setiap peningkatan job characteristcs model sebesar 1,00 maka tingkat employee engagement akan meningkat sebesar 0,798.

Uji t digunakan untuk mengetahui apakah kualitas pelayanan berpengaruh secara signifikan atau tidak terhadap partisipasi anggota koperasi. Pengujian yang dilakukan yakni menggunakan tingkat signifikansi 0,05 dengan uji 2 sisi. Tabel 6 menunjukan nilai t hitung yang besarnya 7,023 dengan menggunakan tingkat signifikansi 5\% dan df: $(n-k)=172-2=170$, maka diperoleh $\mathrm{t}$ tabel sebesar 
1,65387 yang berarti $t_{\text {hitung }}>t_{\text {tabel }}$ yaitu 7,023 > 1,653. Mengacu pada (Sugiyono, 2012:250) yang menyatakan jika Jika tingkat siginifikansi $t_{\text {hitung }}<0,050$ atau $t_{\text {hitung }}>t_{\text {tabel, }}$, maka Ho diterima. Hal tersebut menunjukkan bahwa job characteristics model berpengaruh signifikan terhadap employee engagement.

Tabel 4 R Square

\begin{tabular}{|c|c|c|c|c|}
\hline Model & R & R Square & Adjusted R Square & Std. Error of the Estimate \\
\hline 1 & $0,474 \mathrm{a}$ & 0,225 & 0,220 & 6,685 \\
\hline
\end{tabular}

Tabel 5 Analisis Regresi Linear Sederhana

\begin{tabular}{|l|c|c|c|c|c|}
\hline \multirow{2}{*}{ Model } & \multicolumn{2}{|c|}{ Unstandardized Coefficients } & Standardized Coefficients & \multirow{2}{*}{ T } & Sig. \\
\cline { 2 - 5 } & B & Std. Error & Beta & 4,041 & 0,000 \\
\hline Constant) & 24,792 & 6,136 & & 7,023 & 0,000 \\
\hline
\end{tabular}

Tabel 6 Uji - $t$

\begin{tabular}{|l|c|c|c|c|c|}
\hline \multirow{2}{*}{ Model } & \multicolumn{2}{|c|}{ Unstandardized Coefficients } & Standardized Coefficients & \multirow{2}{*}{ t } & Sig. \\
\cline { 2 - 4 } & B & Std. Error & Beta & 4,04 & 0,000 \\
\hline (Constant) & 24,792 & 6,136 & & 7,02 & 0,000 \\
\hline JCM & 0,798 & 0,114 & 0,474 & & \\
\hline
\end{tabular}

\section{Kesimpulan}

Implementasi job characteristics model yang dilakukan oleh maskapai penerbangan Indonesia sudah baik. Hal itu terlihat dari variabel job characteristics model berada pada kategori sangat baik. Dimana dimensi tertinggi adalah task significance, menunjukan bahwa karyawan sudah sangat sadar bahwa pekerjaan yang dilakukan memiliki pengaruh yang kuat terhadap lingkungan kerja, rekan kerja, dan perusahaan. Namun demikian dari lima dimensi yang terdapat pada job characteristics model terdapat dimensi yang masih berada di bawah rata-rata, yaitu variabel autonomy dan feedback.

Employee engagement pada karyawan maskapai penerbangan Indonesia sudah baik. Dibuktikan dari tiga dimensi berada pada kategori baik. Dimensi yang berperan penting dalam employee engegement karyawa maskapai penerbangan Indonesia adalah dedication, artinya karyawan merasa bahwa pekerjaan yang mereka kerjakan memiliki nilai penghayatan yang tinggi. Namun demikian dimensi absorption dari variabel ini masih berada di bawah rata-rata variabel. Hal ini membuktikan karyawan sulit untuk tenggelam dalam pekerjaan, artinya walaupun pekerjaan dapat memberi dampak emosional positif (vigor) dan memiliki nilai penghayatan yang tinggi, namun karyawan masih sulit untuk fokus secara maksimal saat bekerja.

Job characteristics model yang dimiliki maskapai penerbangan Indonesia berpengaruh sebesar 22\% terhadap employee engagement dilihat dari hasil analisis determinasi korelasi. Artinya terdapat $78 \%$ faktor lain yang tidak dibahas dalam penelitian ini namun berpengaruh lebih tinggi terhadap tingak engagement karyawan.

\section{Daftar Pustaka}

Anitha, J. (2013). Determinants of Employee Engagement and Their Impact on Employee Performance. International Journal of Productivity and Performance Management, 63 (3), 308323.

Arikunto, S. (2010). Prosedur Penelitian: Suatu Pendekatan Praktek. Jakarta: Rineka Cipta.

Broeck, A.V.D., Vansteenkiste, M., Witte, H.D. \& Lens, W. (2008). Explaining The Relationships Between Job Characteristics, Curnout, And Engagement: The Role Of Basic Psychological Need Satisfaction. Work \& Stress: An International Journal Of Work, Health \& Organisations, 22 (3), 277-294

Buckingham, M. \& Coffman, C. (2005). First, Break All The Rules. Sydney: Great Britain by Pocket Books.

Bungin, B. (2010). Metode Penelitian Kualitatif. Jakarta: Rajawali Pers. 
Chaurasia, S. \& Shukla, A. (2013). The Influence Of Leader-Member Exchange Relations On Employee Engagement And Work Role Performance. International Journal Of Organization Theory And Behavior, 16 (4), 465-493.

Darmawan. (2013). Metode Penelitian Kuantitatif. Bandung: Remaja Rosdakarya.

Djastuti, I. (2011). Pengaruh Karakteristik Pekerjaan Terhadap Komitmen Organisasi Karyaw An Tingkat Managerial Perusahaan Jasa Konstruksi Di Jawa Tengah. Jurnal Bisnis dan Akuntansi, 13 (1), 1-19.

Gallup. (2010). Employee Engagement. What is your ration?. http://www.gallup.com/consulting/121535/employee-engagementoverview-brochure.aspx. Diakses tanggal 2 Maret 2018.

Ghozali, I. (2013). Aplikasi Analisis Multivariate Dengan Program IBM SPSS 21 Update PLS Regresi. Semarang: Badan Penerbit Universitas Diponegoro.

Guest, D. (2014). Employee engagement: a sceptical analysis. Journal of Organizational Effectiveness: People and Performance, 1 (2), 141-156.

Gyan, G. (1999). The Effects Of Employee Participation And Work Design On Firm Performance: A Managerial Perspective. Management Research News, 22 (1), 1-12.

Hackman, J.R. \& Oldham, R.G. (1980). Development Of The Job Diagnostic Survey. Journal Applied Psychology, 60 (1), 159-70.

Harter, J.K., Schmidt, F.L., \& Hayes, T.L. (2002). Business-Unit-Level Relationship Between Employee Engagement, Satisfaction, And Business-Unit-Level Outcomes A Meta Analysis. Journal of Applied Psychology, 87 (2), 268-279.

Hartono, J. (2011). Metodologi Penelitian Bisnis: Salah Kaprah dan Pengalaman-pengalaman. Yogyakarta: BPFE.

Husein, U. (2008). Metode Penelitian Untuk Skripsi dan Tesis Bisnis. Jakarta: Rajagrafindo Persada

Indrawati. (2015). Metode Penelitian Manajemen Dan Bisnis Konvergensi Teknologi Komunikasi Dan Informasi. Bandung: Aditama

Karim, I. (2011). Hubungan Desain Kerja Dan Disiplin Dengan Produktivitas Pegawai Direktorat Jenderal Pendidikan Nonformal Dan Informal. Jurnal Manajemen Pendidikan, 2 (2), 308-317.

Kahn, W.A. (1990). Psychological Condition Of Personal Engagement And Disengagement At Work. Academy of Management Journal Boston University, 33 (4), 692-724.

Kreitner, R. \& Kinicki, A. (2007). Perilaku Organisasi. Jakarta: Salemba Empat

Kusuma, E.A. (2012). Peran Perancangan Pekerjaan (Job Design) Pada Employee Engagement. Jurnal akuntansi, manajemen bisnis dan sektor publik (JAMBSP), 9 (1), 74-97.

Luthans, F. (2008). Organizational Behavior. Singapore: McGraw-Hill.

Marciano, P.L. (2010). Carrots and Sticks Don't Work Build a Culture of Employee Engagement with the Principles of RESPECT. Mexico: McGraw Hill.

Mondy, R.W. (2008). Manajemen Sumber Daya Manusia. Terjemahan Bayu Airlangga. Jakarta: Erlangga.

Moorhead, G. \& Griffin, W.R. (2006). Organizational Behaviour - Managing People and Organization. India: ATTBS.

Noe, R.A., Hollenbeck, J.R., Gerhart, B., \& Wright, P.M. (2011). Fundamentals Of Human Resource Management, Fourth Edition. New York: McGraw-Hill.

Noor, J. (2014). Metodologi Penelitian. Jakarta: Kencana.

Pasolong, H. (2012). Teori Administrasi Publik. Yogyakarta: Alfabeta.

Pebrianto, F. (2018). Jumlah Penumpang Pesawat Sepanjang 2017 Tumbuh 9,5 Persen. Dari https://bisnis.tempo.co/read/1062355/jumlah-penumpang-pesawat-sepanjang-2017-tumbuh-95persen. Diakses 20 Maret 2018.

Porter, M. E. (2008). The Five Competitive Forces That Shape Strategy. Harvard Business Review, 86 (1), $1-18$.

Priyatno, D. (2013). Mandiri Belajar Analisis Data Dengan SPSS. Jakarta: Mediakom.

Ram, P. \& Prabhakar, G.V. (2011). The role of employee engagement in work-related outcomes. Interdisciplinary Journal of Research in Business, 1 (3), 47-61.

Rhoades, L. \& Eisenberger, R. (2002). Perceived Organizational Support: A Review Of Literature. Journal Of Applied Psychology, 87 (1), 698-714. 
Riduwan. (2014). Dasar-Dasar Statistika. Bandung: Alfabeta.

Riduwan \& Akdon. (2010). Rumus Dan Data Dalam Analisis Data Statistika. Bandung: Alfabeta.

Robbins, S.P \& Coulter, M. (2007). Management. New Jersey: Pearson Prentice Hall.

Robbins, S.P. \& Judge, T.A. (2007). Perilaku Organisasi. Terjemahan Dian Angelica. Jakarta: Salemba Empat.

Robert, L.M. \& John H. J. (2008). Human Resouce Management. Twelfth Edition. USA: Thomson South-Western.

Robertson, I. T. \& Cooper, C.L. (2010). Full engagement: the integration of employee engagement and psychological well-being. Leadership \& Organization Development Journal, 31 (4), 324-336.

Saks, A.M. (2005). Antecedents and consequences of employee engagement. Journal of Managerial Psychology, 21 (7), 600-619.

Samsiyah, P.S. (2011). Statistika Bisnis untuk Program Diploma IV Manajemen Aset. Bandung: UP MKU Politeknik Negeri Bandung.

Sarder, S., Rehman, A., Yousaf, U., \& Aijaz, A. (2011). Impact Of HR Practices On Employee Engagement In Banking Sector Of Pakistan. Interdisciplinary Journal Of Contemporary Research In Business, 2 (9), 378-389.

Schaufeli, W.B., Leiter, M.P. \& Maslach, C. (2001). Job burnout. Annual Review of Psychology, 52 (1), 397-422.

Schaufeli, W.B. \& Bakker A.B. (2003). Job demands, job resources, and their relationship with burnout and engagement: a multi-sample study. Journal of Organizational Behavior, 25 (1), 293-315.

Schiemann, W.A. (2011). Alignment, Capability, Engagement. Jakarta: PPM

Silalahi, U. (2012). Metode Penelitian Sosial. Bandung: Refika Aditama.

Simons, R. (2000). Performance Measurement and Control Systems for Implementing Strategy: Text and Cases 1st Edition. New Jersey: Prentice-Hal.

Singh, A. (2015). Exploring The Moderating Role Of Context Satisfaction Between Job Characteristics And Turnover Intention. Journal Of Management Development, 34 (1), 1-16.

Slatten, T. \& Mehmetoglu, M. (2011). Antecedents And Effects Of Engaged Frontline Employees: A Study From The Hospital Industry. Managing Service Quality, 21 (1), 88-107.

Sugiyono. (2013). Statistika untuk Penelitian. Bandung: Alfabeta.

Sugiyono. (2011). Metode Penelitian Pendidikan (Pendekatan Kuantitatif, Kualitatif, dan R\&D). Bandung: Alfabeta.

Sugiyono. (2014). Penelitian Pendidikan. Cetakan Ke-20. Bandung: Alfabeta.

Sulea, C., Virga, D., Maricutoiu, L.P., Schaufeli, W., Dumitru, C.Z. \& Sava, F.A. (2012). Work engagement as mediator between job characteristics and positive and negative extra-role behaviors. Career Development International, 17 (3), 188-207.

Sulipan. (2000). Manajemen karyawan. Yogyakarta: Tugu.

Sultan, S. (2012). Examining the Job Characteristics: A Matter of Employees' Work Motivation and Job Satisfaction. Journal of Behavioural Sciences, 22 (2), 21-37.

Tamalero, Y., Swasto, B. \& Hamid D. (2011). Pengaruh karakteristik pekerjaan dan kepuasan kerja terhadap komitmen organisasi dan intention to quit. Jurnal Profit, 6 (2), 23-31.

Taneja, S., Scott, S.S. \& Randall Y.O. (2015). A Culture Of Employee Engagement: A Strategi Perspective For Global Managers. Journal Of Business Strategy, 36 (3), 46 - 56.

Welch, M. (2011). The Evolution Of The Employee Engagement Concept : Communication Implications. Corporate Communications: An International Journal, 16 (4), 328-346.

Wibisono, D. (2003). Riset Bisnis. Jakarta: Gramedia Pustaka Utama.

*Email korespondensi:

gian.rachmana.abs414@polban.ac.id 